\title{
Allelopathic suppression by Conyza canadensis depends on the interaction between latitude and the degree of the plant's invasion
}

\author{
Congyan Wang ${ }^{1 *}$, Kun Jiang', Jiawei Zhou' and Jun Liu'
}

Received: February 7, 2017

Accepted: March 3, 2017

\begin{abstract}
Allelopathic suppression of the growth of co-occurring plant species in invaded ecosystems is an important factor in some plant invasions. This study uses leaf extracts of the invasive plant species Conyza canadensis to determine its allelopathic effects along a latitudinal gradient, and under different cover classes and degrees of invasion, on seed germination and growth of Lactuca sativa, a sensitive bioindicator of allelochemicals. The allelopathic effects of $C$. canadensis on seedling height, root length, seedling biomass, germination percentage, germination potential, germination index, germination rate index, and vigor index of L. sativa increased significantly with increasing latitude. A possible explanation is that the leaves of plants growing in high latitudes secrete a higher concentration of allelochemicals than do leaves of plants growing in low latitudes. The allelopathic effects of $C$. canadensis on seedling height, seedling biomass, germination potential, germination index, germination rate index, and vigor index of $L$. sativa decreased with increasing degree of invasion. The more intense allelopathic effects of $C$. canadensis at lower degrees of invasion may enable it to establish populations in ecosystems by inhibiting the seed germination and growth of co-occurring species.
\end{abstract}

Keywords: allelopathic effects, Conyza canadensis, invasive plant species, Lactuca sativa, seed germination and growth

\section{Introduction}

Plant invasions have inflicted serious damage on the structure and function of native ecosystems (Wang et al. 2016; 2017). Some plants successfully invade certain environments because they can release toxic chemicals and thereby pose an allelopathic effect on seed germination and growth of co-occurring species (Djurdjević et al. 2011; Hu \& Zhang 2013; Wang et al. 2016). Plant invasions can occur in different degrees (i.e., different quantitative cover classes) in colonized ecosystems (Seastedt \& Pyšek 2011; Wang et al.
2017). Meanwhile, the invasion of some plant species (such as Conyza canadensis) can occur across a latitudinal gradient (Yan et al. 2014). At present, the invasive plant species $C$. canadensis has spread into most regions of China (Weber et al. 2008; Hao et al. 2011; Yan et al. 2014). Seed germination and growth are highly important for plant recruitment and resource competition (Weiner et al. 1997; Turk \& Tawaha 2003). The allelopathic effects of invasive plant species can decrease the competitiveness of co-occurring species. Thus, understanding the allelopathic effects of $C$. canadensis across its different invasion degrees along a latitudinal gradient on

\footnotetext{
${ }^{1}$ Institute of Environment and Ecology, Academy of Environmental Health and Ecological Security \& School of the Environment and Safety Engineering, Jiangsu University, Zhenjiang 212013, P. R. China

*Corresponding author: liuyuexue623@163.com
} 
seed germination and growth of co-occurring species may help us understand the mechanism of its successful invasion.

This study aims to understand the allelopathic effects of the invasive plant species $C$. canadensis on seed germination and growth of Lactuca sativa, taking into account invasion degree and latitude. The two plant species occur in the same ecosystem. The invasion degree of $C$. canadensis was evaluated based on its cover classes in the invaded sites. Conyza canadensis is a herbaceous annual invasive weed native to North America (mainly Canada) (Weaver 2001; Hao et al. 2011; Shah et al. 2014). It was first recorded in Yantai, Shandong Province of China in 1862 (Xie et al. 2001; Hao et al. 2011). Conyza canadensis has been listed as one of the most destructive and widespread invasive plant species in China because it poses a serious threat to the diversity and/or abundance of co-occurring plants (Weber et al. 2008; Hao et al. 2011). At present, this species has become a global invader (Zaplata 2011; Djurdjević et al. 2012; Shah et al. 2014). It thrives in many habitats, such as meadows, edges of forests, clearings, orchards, farmland, pond surroundings, stream-banks, and roadsides (Main et al. 2006). Allelopathic effects are hypothesized to explain the successful invasion of C. canadensis (Djurdjević et al. 2011; Hu \& Zhang 2013). The seedlings of L. sativa, one of the most common crops in the region invaded by $C$. canadensis, are sensitive to allelochemicals and the species is widely used as a bioindicator in this type of allelopathy study (Dai et al. 2016; Wang et al. 2016). The results of the present study can provide a platform for better understanding of the mechanisms of successful invasion of $C$. canadensis and provide an important theoretical foundation and practical significance for effective invasion prevention and control.

This study tested the following hypotheses: First, the allelopathic effects of $C$. canadensis leaf extracts on seed germination and growth of L. sativa will increase with increasing latitudinal gradient. This pattern may arise because the leaves of plants that grow in high latitudes secrete higher concentration of allelochemicals compared with those growing in low latitudes due to the lower temperature in high latitudes (Einhellig 1996; Hu \& Kong 2002; Erhard \& Gross 2005). Second, the allelopathic effects of $C$. canadensis leaf extracts on seed germination and growth of $L$. sativa will increase with increasing invasion degree (i.e., cover of $C$. canadensis), because, for a given land area, the quantity of leaves of the invasive plant species at higher degrees of invasion will be higher than the quantity of leaves at low degrees of invasion, and as a result can release more chemical substances.

\section{Materials and methods}

\section{Approach}

From mid-August 2014 to mid-September 2014, samples of $C$. canadensis (L.) Cronq. were obtained from three sampling sites along a latitudinal gradient in China. The high latitude site was Shenyang, with a latitude of $41.82^{\circ} \mathrm{N}$, $123.46^{\circ} \mathrm{E}$ and a cold temperate climate. The annual mean temperature of this site is approximately $8.0^{\circ} \mathrm{C}$, and the temperature reaches a maximum of $38.0^{\circ} \mathrm{C}$ and decreases to a minimum of $-33.0^{\circ} \mathrm{C}$. The annual precipitation at this site is approximately $721.9 \mathrm{~mm}$. The middle latitude site was Jinan, with a latitude of $36.68^{\circ} \mathrm{N}, 116.90^{\circ} \mathrm{E}$ and a warm temperate climate. The annual mean temperature of this site is approximately $13.8^{\circ} \mathrm{C}$, and the temperature reaches a maximum of $42.5^{\circ} \mathrm{C}$ and decreases to a minimum of $-19.0^{\circ} \mathrm{C}$. The annual precipitation at this site is approximately 614.0 $\mathrm{mm}$. The low latitude site was Zhenjiang, with a latitude of $32.20^{\circ} \mathrm{N}, 119.51^{\circ} \mathrm{E}$ and a subtropical monsoon climate. The annual mean temperature of this site is approximately $15.6^{\circ} \mathrm{C}$, and the temperature reaches a maximum of $40.2^{\circ} \mathrm{C}$ and decreases to a minimum of $-10.1{ }^{\circ} \mathrm{C}$. The annual precipitation at this site is approximately $1088.0 \mathrm{~mm}$. (Site climate summaries are derived from local climatological data.) Figure 1 shows the geographic location of the three sampling sites. Samples were taken from weed communities. The invasion degree of $C$. canadensis was determined to be low (<35\%), moderate ( $35 \%$ to $75 \%$ ), or high ( $>75 \%$ ) on the basis of its cover classes in each sampling site. Three plant individuals of $C$. canadensis were collected randomly from each of three quadrats $(1 \mathrm{~m} \times 1 \mathrm{~m})$ in each of three sampling sites at a given invasion degree (3 plant individuals $\times 3$ quadrat repeats $\times 3$ invasion degrees $\times 3$ sampling sites $=81$ plant individuals). The seeds of Lactuca sativa L., native to East Asia, were purchased from a local vegetable market. Lactuca sativa, one of the most popular vegetables in China, is widely used as both a vegetable and a traditional medicine (Han et al. 2010).

After collection, the samples were processed to derive chemical extracts from the leaves. The leaf extract was obtained by placing $10 \mathrm{~g}$ of air-dried leaf tissue of $C$. canadensis in flasks containing $500 \mathrm{~mL}$ of distilled water and soaked for $48 \mathrm{~h}$ at room temperature. The resulting extract was strained through cheesecloth and then through two layers of filter paper to remove solid material. The stock solution was stored at $4^{\circ} \mathrm{C}$ for no more than one week for further study and diluted with distilled water prior to use. The concentration of leaf extracts was set at $20 \mathrm{~g} \mathrm{~L}^{-1}$ with distilled water as control (CK).

\section{Seed germination experiment}

The seed germination treatments included three latitudinal gradient and three invasion degrees. A total of ten treatment combinations were devised as follows: Control (fertilized with sterile distilled water only, CK), SY-L (the extracts of $C$. canadensis leaves collected from Shenyang from locations displaying a low invasion degree), SY-M (the extracts of $C$. canadensis leaves collected from Shenyang from locations displaying a moderate invasion degree), SY-H (the 


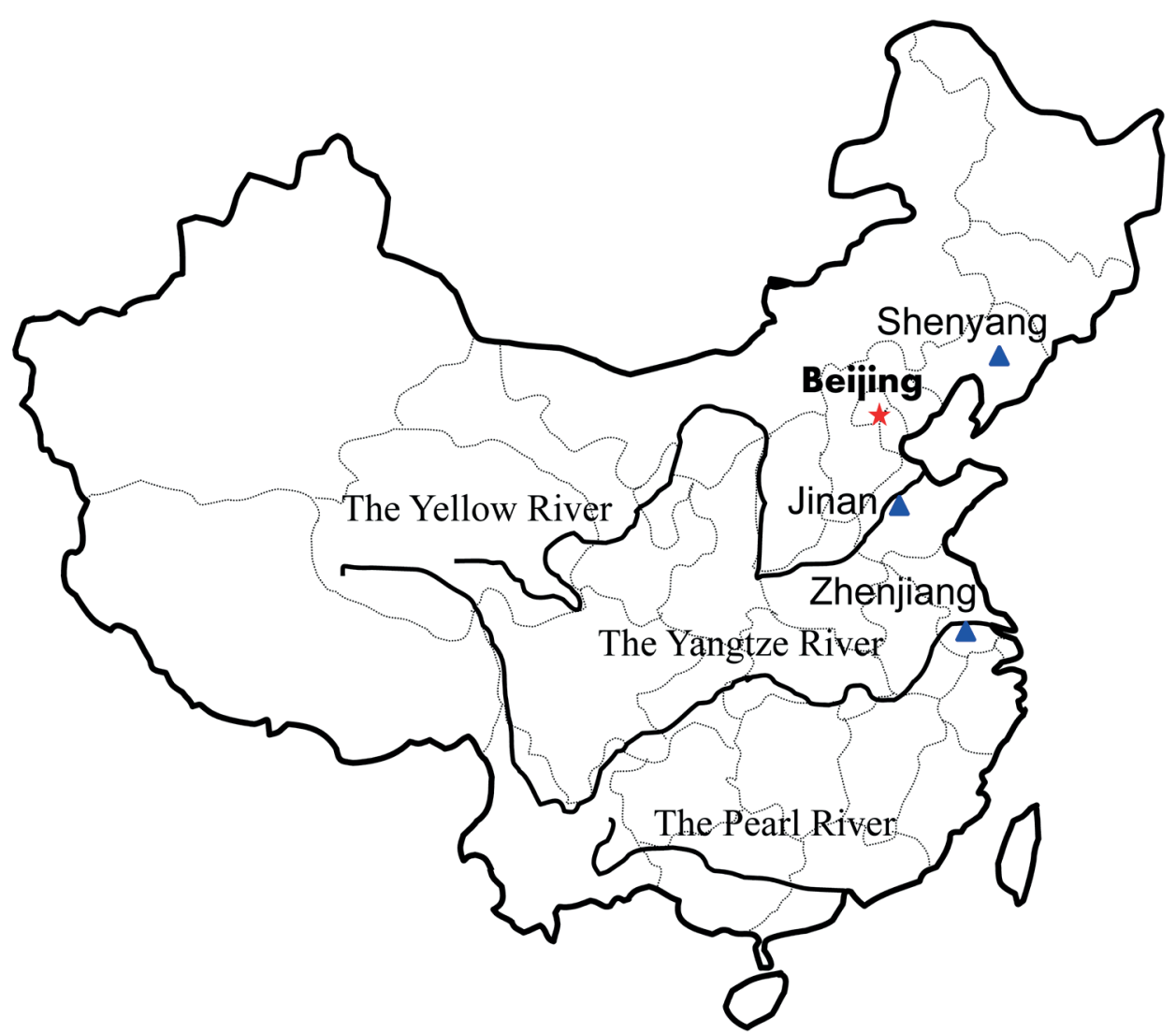

Figure 1. The local geographic location of the three sampling sites. The triangles represent the geographic location of the three sampling sites.

extracts of $C$. canadensis leaves collected from Shenyang from locations displaying a high invasion degree), JN-L (the extracts of $C$. canadensis leaves collected from Jinan from locations displaying a low invasion degree), JN-M (the extracts of $C$. canadensis leaves collected from Jinan from locations displaying a moderate invasion degree), JN-H (the extracts of $C$. canadensis leaves collected from Jinan from locations displaying a high invasion degree), ZJ-L (the extracts of $C$. canadensis leaves collected from Zhenjiang from locations displaying a low invasion degree), ZJ-M (the extracts of $C$. canadensis leaves collected from Zhenjiang from locations displaying a moderate invasion degree), and ZJ-H (the extracts of $C$. canadensis leaves collected from Zhenjiang from locations displaying a high invasion degree). Seed germination experiments were conducted through incubation in Petri dishes (Wang et al. 2016). Lactuca sativa seeds were surface sterilized (soaked in $1 \% \mathrm{NaClO}$ for approximately $15 \mathrm{~min}$ ) and then washed thoroughly three times with deionized water. Thirty visibly full seeds were placed in a Petri dish of $9 \mathrm{~cm}$ diameter and covered with two layers of filter paper. The seeds were treated with 10 $\mathrm{mL}$ of $C$. canadensis leaf extracts or sterile deionized water (control, CK). The Petri dishes were placed in a climatecontrolled incubator at $27^{\circ} \mathrm{C}$ (Thompson et al. 1979) for $7 \mathrm{~d}$ with $10 \mathrm{~h}$ light per day (light intensity was set at $27.5 \mu \mathrm{mol}$ $\mathrm{m}^{-2} \mathrm{~s}^{-1}$ ). Five replicate dishes were prepared per treatment.
The number of germinated seeds was counted every day during incubation time, and the seeds were considered germinated when the radicle had emerged from the seed (Wang et al. 2016).

\section{Seedling growth experiment}

The same treatments as described above for the seed germination experiment were used for the seedling growth experiment. Ten uniformly sized and strongly growing seedlings per Petri dish were randomly selected for seedling growth measurement at the end of the germination experiment. Seedling height (indicative of the seedling's competitive ability for light; Moles et al. 2009), root length (indicative of the seedling's competitive ability for nutrition; James 2008), seedling biomass (fresh weight) (indicative of growth competitiveness; Burns 2004), germination percentage (indicative of the germination ability of seeds), germination potential (indicative of the germination speed and uniformity of seeds), germination index, germination rate index, and vigor index (indicative of the germination speed and vitality of seeds) of L. sativa L. were determined. Seedling height and root length were measured using a ruler (Wang et al. 2016). Seedling biomass was determined using an electronic balance with an accuracy of $0.001 \mathrm{~g}$ (Gong et al. 2001; Wang et al. 2016). 
Germination percentage was calculated using the ratio of the final number of germinated seeds to the total number of the test seeds when no new germination occurred after $7 \mathrm{~d}$ of incubation (Wang et al. 2016). Germination potential was determined by dividing the number of germinated seeds on the third day by the total number of the test seeds (Wang et al. 2016). Germination index was calculated using the following equation: Germination index $=\sum G_{i} / I$, where $G_{i}$ represents the number of germinated seeds, and $I$ represents the number of days after initial seed cultivation (Schmer et al. 2012; Hou et al. 2014). Germination rate index was calculated using the following equation: GRI = Germination percentage $\times$ Germination index (Steinmaus et al. 2000). Vigor index was determined using the following equation: Vigor index $=$ Seedling biomass $\times$ Germination index (Lin et al. 2000).

\section{Statistical analyses}

Differences among dependent variables were assessed using analysis of variance between treatment groups followed by the Student-Newman-Keuls test for multiple comparisons. Two-way ANOVAs were applied to evaluate the effects of latitudinal gradient and invasion degree on seed germination and growth of L. sativa using SPSS Statistics (version 22.0; IBM, Armonk, NY, USA). Statistical significance was set at $P$ values equal to or lower than 0.05 .

\section{Results}

The effects of $C$. canadensis leaf extracts derived from weed populations in the three sampling sites exerted negative effects on root length of $L$. sativa $(P<0.05$; Tab. 1$)$. The effects of $C$. canadensis leaf extracts from populations in Shenyang exerted negative effects on seedling biomass, germination potential, and germination potential of L. sativa $(P<0.05 ;$ Tab. 1$)$. The effects of $C$. canadensis leaf extracts from populations in Jinan and Shenyang also exerted negative effects on germination percentage, germination index, germination rate index, and vigor index of $L$. sativa $(P$ $<0.05$; Tab. 1). Meanwhile, the effects of $C$. canadensis leaf extracts from all invasion degrees samples exerted negative effects on root length, germination index, and germination rate index of $L$. sativa $(P<0.05$; Tab. 2). The effects of $C$. canadensis leaf extracts from low invasion-degree samples also exerted negative effects on vigor index of $L$. sativa $(P<0.05$; Tab. 2).

The effects of $C$. canadensis leaf extracts on all indices of $L$. sativa increased significantly with increasing latitude across Zhenjiang, Jinan, and Shenyang $(P<0.05$; Tab. 1$)$. Meanwhile, the effects of $C$. canadensis leaf extracts on root length, germination index, germination rate index and vigor index of $L$. sativa decreased with the different invasion degree $(P<0.05 ;$ Tab. 2$)$. No significant effect of invasion degree was observed for seedling height, seedling biomass, germination percentage, and germination potential of $L$. sativa $(P>0.05$; Tab. 2$)$.

The effects of $C$. canadensis leaf extracts from low and moderate invasion degrees samples in Shenyang on seedling height, root length, seedling biomass, germination potential, germination index, germination rate index, and vigor index of $L$. sativa were significantly higher than those from the same invasion degrees in Zhenjiang and Jinan $(P<0.05$; Fig. 2). Meanwhile, the effects of $C$. canadensis leaf extracts from low invasion-degree samples in Shenyang on the germination percentage of $L$. sativa were significantly higher than those from the same invasion degree in Zhenjiang and Jinan $(P<$ 0.05 ; Fig. 2). The effects of $C$. canadensis leaf extracts from low invasion-degree samples in the three sampling sites on root length and vigor index of $L$. sativa decreased in the following order: Shenyang $>$ Jinan $>$ Zhenjiang $(P<0.05$; Fig. 2). Meanwhile, the effects of $C$. canadensis leaf extracts from moderate invasion-degree samples in the three sampling sites on seedling height, root length, seedling biomass, germination potential, germination index, germination rate index, and vigor index of $L$. sativa decreased in the following order: Shenyang $>$ Jinan $>$ Zhenjiang $(P<0.05$; Fig. 2). However, there was no significant difference in the effects of $C$. canadensis leaf extracts from high invasiondegree samples on all indices of $L$. sativa among the three sampling sites $(P<0.05$; Fig. 2$)$.

In Shenyang the effects of $C$. canadensis leaf extracts from low and moderate invasion degrees on seedling height, root length, seedling biomass, germination potential, germination index, germination rate index, and vigor index of $L$. sativa were significantly higher than those from the high invasion degree $(P<0.05 ;$ Fig. 2$)$. However, there was no significant difference among the three invasion degrees in the effects of $C$. canadensis leaf extracts from populations in Jinan on all indices of $L$. sativa performance $(P<0.05$; Fig. 2). Meanwhile, for the samples from Zhenjiang, the effects of $C$. canadensis leaf extracts from low and moderate invasion degrees on germination potential and germination index of $L$. sativa were significantly lower than those from the high invasion degree $(P<0.05$; Fig. 2). In Zhenjiang the effects of $C$. canadensis leaf extracts from low invasion degree on seedling height of $L$. sativa were significantly lower than those from the high invasion degree $(P<0.05$; Fig. 2$)$. The effects of $C$. canadensis leaf extracts from populations in Zhenjiang on root length of L. sativa decreased in the following order: moderate invasion degree $>$ low invasion degree $>$ high invasion degree $(P<0.05$; Fig. 2$)$.

The results of the ANOVAs revealed that latitude and the interaction between latitude and invasion degree exert significant effects on all indices of $L$. sativa growth and germination, while invasion degree significantly affected only seedling height, seedling biomass, and the germination potential of L. sativa (Tab. 3, $P<0.05$ ). 
Table 1. Differences in the indices of $L$. sativa under the addition of $C$. canadensis leaf exacts with different latitudinal gradients. Data with different letters in a vertical row indicate a significant difference $(P<0.05)$. Abbreviations: $\mathrm{H}$, seedling height $(\mathrm{cm})$; RL, root length (cm); BM, seedling biomass (g); GPe, germination percentage (\%); GPo, germination potential (\%); GI, germination index; GRI, germination rate index; VI, vigor index.

\begin{tabular}{|c|c|c|c|c|c|c|c|c|c|}
\hline & H & RL & BM & GPe & GPo & GI & GRI & VI \\
\hline $\begin{array}{c}\text { Control } \\
\text { Low } \\
\text { latitude }\end{array}$ & $2.14 \pm 0.11 \mathrm{~b}$ & $3.10 \pm 0.49 \mathrm{a}$ & $0.20 \pm 0.01 \mathrm{a}$ & $90.00 \pm 2.79 \mathrm{a}$ & $76.00 \pm 1.63 \mathrm{a}$ & $52.58 \pm 1.40 \mathrm{a}$ & $47.29 \pm 1.77 \mathrm{a}$ & $10.71 \pm 0.58 \mathrm{a}$ \\
\hline $\begin{array}{c}\text { Middle } \\
\text { latitude }\end{array}$ & $2.64 \pm 0.04 \mathrm{a}$ & $1.97 \pm 0.08 \mathrm{~b}$ & $0.22 \pm 0.01 \mathrm{a}$ & $86.67 \pm 1.22 \mathrm{ab}$ & $76.67 \pm 2.16 \mathrm{a}$ & $44.49 \pm 1.83 \mathrm{ab}$ & $38.71 \pm 1.94 \mathrm{ab}$ & $9.70 \pm 0.55 \mathrm{ab}$ \\
$\begin{array}{c}\text { High } \\
\text { latitude }\end{array}$ & $2.08 \pm 0.25 \mathrm{~b}$ & $0.99 \pm 0.14 \mathrm{~d}$ & $0.13 \pm 0.02 \mathrm{~b}$ & $75.13 \pm 4.11 \mathrm{c}$ & $34.36 \pm 8.75 \mathrm{~b}$ & $23.96 \pm 4.44 \mathrm{~d}$ & $19.80 \pm 4.31 \mathrm{c}$ & $3.93 \pm 1.04 \mathrm{c}$ \\
\hline
\end{tabular}

Table 2. Differences in the indices of $L$. sativa under the addition of $C$. canadensis leaf exacts with different invasion degrees. Data with different letters in a vertical row indicate a significant difference $(P<0.05)$. "ns" means no significant difference $(P>0.05)$. Abbreviations: H, seedling height (cm); RL, root length (cm); BM, seedling biomass (g); GPe, germination percentage (\%); GPo, germination potential (\%); GI, germination index; GRI, germination rate index; VI, vigor index.

\begin{tabular}{|c|c|c|c|c|c|c|c|c|c|} 
& H & RL & BM & GPe & GPo & GI & GRI \\
\hline Control & $2.14 \pm 0.11 \mathrm{~ns}$ & $3.10 \pm 0.49 \mathrm{a}$ & $0.20 \pm 0.01 \mathrm{~ns}$ & $90.00 \pm 2.79 \mathrm{~ns}$ & $76.00 \pm 1.63 \mathrm{~ns}$ & $52.58 \pm 1.40 \mathrm{a}$ & $47.29 \pm 1.77 \mathrm{a}$ & $10.71 \pm 0.58 \mathrm{a}$ \\
\hline Low degree & $2.47 \pm 0.24 \mathrm{~ns}$ & $1.35 \pm 0.17 \mathrm{~b}$ & $0.17 \pm 0.02 \mathrm{~ns}$ & $78.22 \pm 3.33 \mathrm{~ns}$ & $55.78 \pm 9.03 \mathrm{~ns}$ & $33.49 \pm 4.32 \mathrm{~b}$ & $27.86 \pm 3.97 \mathrm{~b}$ & $6.65 \pm 1.11 \mathrm{~b}$ \\
\hline Moderate degree & $2.52 \pm 0.16 \mathrm{~ns}$ & $1.71 \pm 0.15 \mathrm{~b}$ & $0.18 \pm 0.01 \mathrm{~ns}$ & $79.49 \pm 2.77 \mathrm{~ns}$ & $60.77 \pm 7.39 \mathrm{~ns}$ & $36.73 \pm 3.92 \mathrm{~b}$ & $30.11 \pm 3.79 \mathrm{~b}$ & $7.26 \pm 1.06 \mathrm{ab}$ \\
\hline High degree & $2.88 \pm 0.06 \mathrm{~ns}$ & $1.47 \pm 0.06 \mathrm{~b}$ & $0.20 \pm 0.01 \mathrm{~ns}$ & $84.67 \pm 1.55 \mathrm{~ns}$ & $72.22 \pm 2.15 \mathrm{~ns}$ & $39.34 \pm 1.47 \mathrm{~b}$ & $33.52 \pm 1.77 \mathrm{~b}$ & $8.00 \pm 0.44 \mathrm{ab}$ \\
\hline
\end{tabular}

\section{Discussion}

Allelopathy is any beneficial or deleterious effects of plant species on the growth or development of another biological system, through the release of chemicals into the environment. These chemical compounds, known as allelochemicals, are secondary metabolites produced naturally by plant species (Ma et al. 2012; Gomaa et al. 2014). Previous studies have revealed that the allelopathic effects of invasive plant species, including $C$. canadensis (Djurdjević et al. 2011; 2012), on co-occurring species are mainly due to secondary metabolites (Svensson et al. 2013; Macel et al. 2014).

Consistent with previous reports (Djurdjević et al. 2011; $\mathrm{Hu} \&$ Zhang 2013), our results indicated that $C$. canadensis exerts significant allelopathic effects on seed germination and growth of L. sativa. Our findings are consistent with the Novel Weapons Hypothesis, i.e., that some invaders are successful because they possess novel biochemical weapons that function as unusually powerful allelopathic agents, or as mediators of new plant-soil microbial interactions (Callaway \& Ridenour 2004).

The invasion of $C$. canadensis currently occurs across a latitudinal gradient in China. The allelopathic effects of $C$. canadensis on the growth of co-occurring species vary across latitudinal gradients due to differences in precipitation, temperature, and sunlight. Latitudinal gradients may affect biomass production and resource allocation (Wright et al. 2005; Frenne et al. 2013), and these patterns may influence the secretion of allelochemicals (Šèžienè et al. 2012; Gatti et al. 2014). Previous investigations have found that plants that grow in high latitudes pay more allocation of biomass into leaf construction (Wright et al. 2005; Reef \& Lovelock 2014). Based on this, the leaves of plants that grow in high latitudes are likely to contain higher concentrations of secondary metabolites compared with those growing in low latitudes (Wright et al. 2004; Macel et al. 2014).

The increase in allelopathic effects of $C$. canadensis leaf extracts on all indices of $L$. sativa with increasing latitudinal gradient (Tab. 1) was consistent with the study's hypothesis. Previous studies also showed that climatic conditions (such as precipitation and temperature) can affect plant secondary metabolism and change plant allelopathic activity by altering the production of allelochemicals (Šěžienè et al. 2012; Gatti et al. 2014). Meanwhile, as environmental conditions become stressful for plant growth, the allelochemical contents of a plant dramatically increases due to the increase production of carbon-based defensive substances, which are secondary metabolism derivatives (An 2005; Gatti et al. 2014). Previous studies also revealed that the concentration of allelochemicals of plant species under low temperature was higher than the concentration under high temperature (Einhellig 1996; $\mathrm{Hu} \&$ Kong 2002; Erhard \& Gross 2005). The phenomenon may also be attributed to the fact that $C$. canadensis is native to Canada (Weaver 2001), which has similar climatic conditions as Shenyang (the high latitude site) due to their similar latitudes. This outcome suggestes that the inhibitory allelopathic effects of $C$. canadensis on seed germination and growth of co-occurring species may play an important role in its successful invasion, especially in high latitudes.

Meanwhile, C. canadensis displays different invasion degrees in its invaded ecosystems. The allelopathic effects of $C$. canadensis on the growth of co-occurring species may be significantly affected by its invasion degree due to intraspecific competition (Sheppard \& Burns 2014). 

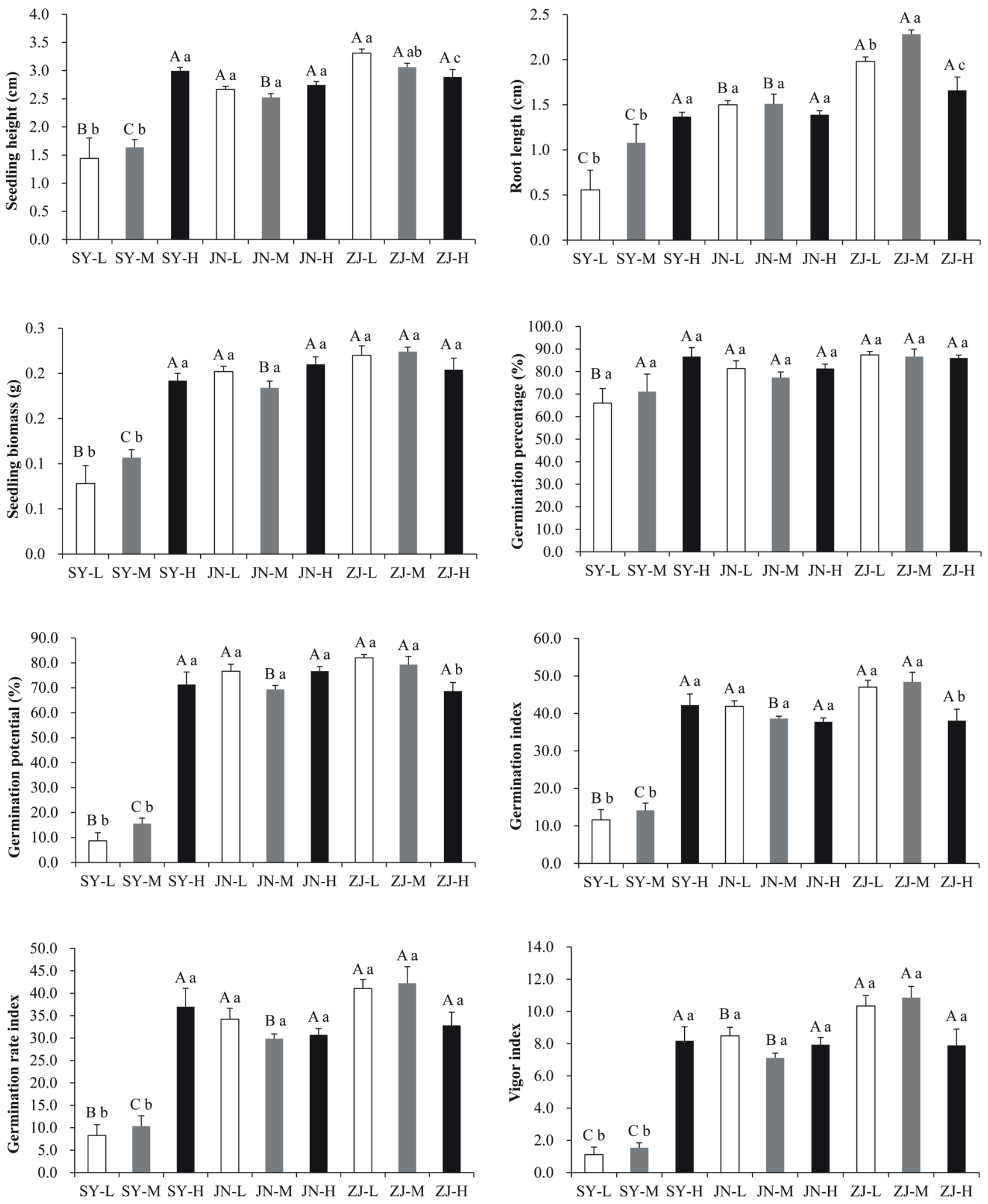

Figure 2. The indices of $L$. sativa under the addition of $C$. canadensis leaf exacts with different invasion degrees (L, low; $M$, moderate; $\mathrm{H}$, high) along a latitudinal gradient (SY, Shenyang; JN, Jinan; ZJ, Zhenjiang). Data with different capital letters indicate a significant difference between the three sampling sites at the same invasion degree and data with different lower case letters indicate a significant difference between the three invasion degrees in the same sampling site $(P<0.05)$. Note: white bar, low invasion degree; grey bar, medium invasion degree; black bar, high invasion degree. 
Table 3. Two-way ANOVAs on the effects of latitude gradient and invasion stage on the indices of L. sativa. Abbreviations: H, seedling height (cm); RL, root length (cm); BM, seedling biomass (g); GPe, germination percentage (\%); GPo, germination potential (\%); GI, germination index; GRI, germination rate index; VI, vigor index.

\begin{tabular}{|l|c|c|c|c|c|c|c|c|c|c|c|c|c|c|}
\hline & & PH & RL & BM & GPe & GPo & GI & GRI & VI \\
\hline Latitude gradient & $F$ & 26.97 & 38.13 & 33.04 & 6.06 & 96.82 & 51.46 & 29.38 \\
& $P$ & $<0.0001$ & $<0.0001$ & $<0.0001$ & 0.0014 & $<0.0001$ & $<0.0001$ & $<0.0001$ & $<0.0001$ \\
\hline Invasion stage & $F$ & 4.09 & 1.52 & 4.05 & 1.60 & 12.84 & 1.29 & 1.17 & 0.89 \\
\hline & $P$ & 0.0232 & 0.2298 & 0.0240 & 0.2121 & $<0.0001$ & 0.2845 & 0.3196 & 0.4163 \\
\hline Latitude gradient & $*$ & $F$ & 12.81 & 7.28 & 9.26 & 2.90 & 30.34 & 24.52 & 15.28 & 16.15 \\
\hline Invasion stage & $P$ & $<0.0001$ & $<0.0001$ & $<0.0001$ & 0.0174 & $<0.0001$ & $<0.0001$ & $<0.0001$ & $<0.0001$ \\
\hline
\end{tabular}

Generally, intraspecific competition increases with increasing invasion degree. As a result, invasive plant species must achieve a higher growth rate to obtain more resources (including space resources and nutrient resources) and achieve as large of a fitness advantage as possible under the changing conditions. As a result, invasive plant species at higher invasion degrees invest low biomass in leaf structures per unit area to gain a higher growth rate compared with plants growing at lower invasion degrees. Previous investigations have also found that the biomass investment per unit of leaf area was correlated positively with population density (Liu et al. 2009; Tobin et al. 2011). Hence, plants growing at higher invasion degrees may allocate less biomass to leaf construction in order to yield high resource acquisition and use efficiency (James \& Drenovsky 2007; Shen et al. 2011). Accordingly, the leaves of plants that grow at higher invasion degrees may contain lower concentrations of secondary metabolites compared with plants growing at lower invasion degrees. This is consistent with the finding that the allelopathic effects of $C$. canadensis leaf extracts on seed germination and growth (seedling height, seedling biomass, germination potential, germination index, germination rate index, and vigor index) of L. sativa decreased with increasing invasion degree (Tab. 2). The result was inconsistent with the study's hypothesis. It indicates that the inhibitory allelopathic effects of $C$. canadensis on the seed germination and growth of co-occurring species may be attenuated at higher invasion degrees. More importantly, the intensified allelopathic effects of invasive plant species at lower invasion degrees can enable the invader to establish rapidly-growing populations in invaded ecosystems via inhibition of the seed germination and growth of co-occurring species.

\section{Conclusion}

Conyza canadensis exhibits negative allelopathic effects on the seed germination and growth of L. sativa. This effect increases with increasing latitudinal gradient but decreases with increasing invasion degree. The inhibitory allelopathic effects of $C$. canadensis on the seed germination and the growth of co-occurring species may be crucial to its successful invasion, especially when this species occurs at lower invasion degrees as well as in high latitudes.

\section{Acknowledgements}

This study was supported by National Natural Science Foundation of China (31300343). We are very grateful to the anonymous reviewers for the insightful and constructive comments that greatly improved this manuscript.

\section{References}

An M. 2005. Mathematical modelling of dose-response relationship (hormesis) in allelopathy and its application. Nonlinearity in Biology, Toxicology, and Medicine 3: 153-172.

Burns JH. 2004. A comparison of invasive and non-invasive dayflowers (Commelinaceae) across experimental nutrient and water gradients. Diversity and Distributions 10: 387-397.

Callaway RM, Ridenour WM. 2004. Novel weapons: invasive success and the evolution of increased competitive ability. Frontiers in Ecology and the Environment 2: 436-443.

Dai ZC, Wang XY, Qi SS, et al. 2016. Effects of leaf litter on inter-specific competitive ability of the invasive plant Wedelia trilobata. Ecological Research 31: 367-374.

Djurdjević L, Gajić G, Kostić O, et al. 2012. Seasonal dynamics of allelopathically significant phenolic compounds in globally successful invader Conyza canadensis L. plants and associated sandy soil. Flora 207: 812-820.

Djurdjević L, Mitrović M, Gajić G, et al. 2011. An allelopathic investigation of the domination of the introduced invasive Conyza canadensis L.. Flora 206: 921-927.

Einhellig FA. 1996. Interactions involving allelopathy in cropping systems. Agronomy Journal 88: 886-893.

Erhard D, Gross E. 2005. Do environmental factors influence composition of potential allelochemicals in the submersed freshwater macrophyte Elodea nuttallii (Hydrocharitaceae)? Verhandlungen der Internationalen Vereinigung für Limnologie 29: 287-291.

Frenne P, Graae BJ, Rodríguez-Sánchez F, et al. 2013. Latitudinal gradients as natural laboratories to infer species' responses to temperature. Journal of Ecology 101: 784-795.

Gatti AB, Takao LK, Pereira VC, Ferreira AG, Lima MIS, Gualtieri SCJ. 2014. Seasonality effect on the allelopathy of cerrado species. Brazilian Journal of Biology 74: S064-S069.

Gomaa NH, Hassan MO, Fahmy GM, González L, Hammouda O, Atteya AM. 2014. Allelopathic effects of Sonchus oleraceus L. on the germination and seedling growth of crop and weed species. Acta Botanica Brasilica 28: 408-416.

Gong P, Wilke BM, Strozzi E, Fleischmann S. 2001. Evaluation and refinement of a continuous seed germination and early seedling growth test for the use in the ecotoxicological assessment of soils. Chemosphere 44: 491-500.

Han YF, Cao GX, Gao XJ, Xia M. 2010. Isolation and characterisation of the sesquiterpene lactones from Lactuca sativa $L$ var. anagustata. Food chemistry 120: 1083-1088. 


\section{Allelopathic suppression by Conyza canadensis depends on the interaction between latitude and the degree of the plant's invasion}

Hao JH, Qiang S, Chrobock T, Kleunen M, Liu QQ. 2011. A test of Baker's law: breeding systems of invasive species of Asteraceae in China. Biological Invasions 13: 571-580.

Hou QQ, Chen BM, Peng SL, Chen LY. 2014. Effects of extreme temperature on seedling establishment of nonnative invasive plants. Biological Invasions 16: 2049-2061.

Hu F, Kong C. 2002. Allelopathy of Ageratum conyzoides. VI. Effects of meteorological conditions on allelopathy of Ageratum conyzoides. The Journal of Applied Ecology 13: 76-80.

Hu G, Zhang ZH. 2013. Aqueous tissue extracts of Conyza canadensis inhibit the germination and shoot growth of three native herbs with no autotoxic effects. Planta Daninha 31: 805-811.

James JJ. 2008. Leaf nitrogen productivity as a mechanism driving the success of invasive annual grasses under low and high nitrogen supply. Journal of Arid Environments 72: 1775-1784.

James JJ, Drenovsky RE. 2007. A basis for relative growth rate differences between native and invasive forb seedlings. Rangeland Ecology \& Management 60: 395-400.

Lin WX, Kim KU, Smin DH. 2000. Rice allelopathic potential and its modes of action on barnyardgrass (Echinochloa crusgalli). Allelopathy Journal 7: 215-224.

Liu TF, Zhang CL, Yang GS, et al. 2009. Central composite design-based analysis of specific leaf area and related agronomic factors in cultivars of rapeseed (Brassica napus L.). Field Crops Research 111: 92-96.

Ma JH, Xing GF, Yang WX, et al. 2012. Inhibitory effects of leachate from Eupatorium adenophorum on germination and growth of Amaranthus retroflexus and Chenopodium glaucum. Acta Ecologica Sinica 32: 50-56.

Macel M, Vos RCH, Jansen JJ, Putten WH, Dam NM. 2014. Novel chemistry of invasive plants: exotic species have more unique metabolomic profiles than native congeners. Ecology and Evolution 4: 2777-2786.

Main CL, Steckel LE, Hayes RM, Mueller TC. 2006. Biotic and abiotic factors influence horseweed emergence. Weed Science 54: 1101-1105.

Moles AT, Warton DI, Warman L, et al. 2009. Global patterns in plant height. Journal of Ecology 97: 923-932.

Reef R, Lovelock CE. 2014. Historical analysis of mangrove leaf traits throughout the 19th and 20th centuries reveals differential responses to increases in atmospheric $\mathrm{CO}_{2}$. Global Ecology Biogeography 23: 1209-1214.

Schmer MR, Xue Q, Hendrickson JR. 2012. Salinity effects on perennial, warm-season (C4) grass germination adapted to the northern Great Plains. Canadian Journal of Plant Science 92: 873-881.

Seastedt TR, Pyšek P. 2011. Mechanisms of plant invasions of North America and European grasslands. Annual Review of Ecology Evolution and Systematics 42: 133-153.

Šèžienè V, Baležentienè L, Ozolinčius R. 2012. Allelopathic impact of some dominants in clean cuttings of Scots pine forest under climate change conditions. Ekologija 58: 59-64

Shah MA, Callaway RM, Shah T, et al. 2014. Conyza canadensis suppresses plant diversity in its nonnative ranges but not at home: a transcontinental comparison. New Phytologist 202: 1286-1296.

Shen XY, Peng SL, Chen BM, et al. 2011. Do higher resource capture ability and utilization efficiency facilitate the successful invasion of native plants?. Biological Invasions 13: 869-881.

Sheppard CS, Burns BR. 2014. Effects of interspecific alien versus intraspecific native competition on growth of native woody plants. Plant Ecology 215: 1527-1538.

Steinmaus SJ, Timonthy SP, Jodie SH. 2000. Estimation of base temperature for nine weed species. Journal of Experimental Botany 51: 275-286.

Svensson JR, Nylund GM, Cervin G, Toth GB, Pavia H. 2013. Novel chemical weapon of an exotic macroalga inhibits recruitment of native competitors in the invaded range. Journal of Ecology 101: 140-148.

Thompson PA, Cox SA, Sanderson RH. 1979. Characterization of the germination responses to temperature of lettuce (Lactuca sativa L.) achenes. Annals of Botany 43: 319-334.

Tobin PC, Berec L, Liebhold AM. 2011. Exploiting Allee effects for managing biological invasions. Ecology Letters 14: 615-624.

Turk MA, Tawaha AM. 2003. Allelopathic effect of black mustard (Brassica nigra L.) on germination and growth of wild oat (Avena fatua L.). Crop Protection 22: 673-677.

Wang CY, Xiao HG, Zhao LL, et al. 2016. The allelopathic effects of invasive plant Solidago canadensis on seed germination and growth of Lactuca sativa enhanced by different types of acid deposition. Ecotoxicology 25: 555-562.

Wang CY, Zhou JW, Liu J, Wang L, Xiao HG. 2017. Reproductive allocation strategy of two herbaceous invasive plants across different cover classes. Polish Journal of Environmental Studies 26: 355-364.

Weaver SE. 2001. The biology of Canadian weeds. 115. Conyza canadensis. Canadian Journal of Plant Science 81: 867-875.

Weber E, Sun SQ, Li B. 2008. Invasive alien plants in China: diversity and ecological insights. Biological Invasions 10: 1411-1429.

Weiner J, Wright DB, Castro S. 1997. Symmetry of below-ground competition between Kochia scoparia individuals. Oikos 79: 85-91.

Wright IJ, Reich PB, Cornelissen JHC, et al. 2005. Modulation of leaf economic traits and trait relationships by climate. Global Ecology Biogeography 14: 411-421.

Wright IJ, Reich PB, Westoby M, et al. 2004. The worldwide leaf economics spectrum. Nature 428: 821-827.

Xie Y, Li ZY, Gregg WP, Dianmo L. 2001. Invasive species in China-an overview. Biodiversity and Conservation 10: 1317-1341.

Yan XL, Liu QR, Shou HY, et al. 2014. The categorization and analysis on the geographic distribution patterns of Chinese alien invasive plants. Biodiversity Science 22: 667-676.

Zaplata MK, Winter S, Biemelt D, Fischer A. 2011. Immediate shift towards source dynamics: the pioneer species Conyza canadensis in an initial ecosystem. Flora 206: 928-934. 